\title{
Perbandingan efektivitas pemberian asam mefenamat dan natrium diklofenak sebelum pencabutan gigi terhadap durasi ambang nyeri setelah pencabutan gigi
}

\author{
${ }^{1}$ Kartika Pangalila \\ ${ }^{2}$ Pemsi M. Wowor \\ ${ }^{3}$ Bernat S. P. Hutagalung
}

\author{
${ }^{1}$ Kandidat Skripsi Program Studi Pendidikan Dokter Gigi Fakultas Kedokteran \\ ${ }^{2}$ Bagian Farmakologi dan Terapi Fakultas Kedokteran \\ ${ }^{3}$ Program Studi Pendidikan Dokter Gigi Fakultas Kedokteran \\ Universitas Sam Ratulangi Manado \\ Email: pangalilakartika@gmail.com
}

\begin{abstract}
Tooth extraction is one of a minor operative surgery in dentistry that could cause uncomfortable sense of pain at its surrounding area. In order to reduce that feeling, some pain management could be performed, such as local anesthetic administration or analgesic medication. This study aimed to compare the effectiveness of mefenamic acid and diclofenac sodium given before the extraction procedure against the pain threshold duration after tooth extraction. This was a clinical study with a case-control design and was carried out in July $11^{\text {th }}$ - August $12^{\text {th }} 2016$ at Department of Oral Surgery RSGM FK Unsrat. There were 30 samples obtained by using the purposive sampling method, divided into three groups, each of 10 samples, as follows: the control group without any analgesic treatment; the treated group with mefenamic acid; and another treated group with diclofenac sodium before the extraction. The results showed that the control group had a lower average of pain threshold duration than the treated groups with a difference of 2 hours and 42 minutes. The group treated with mefenamic acid before the extraction had the highest average of pain threshold duration compared to the group of diclofenac sodium with 4 hours and 11 minutes vs. 3 hours and 49 minutes. Conclusion: Mefenamic acid given before the tooth extraction procedure had greater effect and higher pain threshold duration than diclofenac sodium.
\end{abstract}

Keywords: tooth extraction, mefenamic acid, diclofenac sodium, pain threshold duration.

\begin{abstract}
Abstrak: Pencabutan gigi merupakan salah satu tindakan dalam bidang kedokteran gigi yang dapat menimbulkan rasa nyeri akibat adanya trauma pada soket gigi yang dicabut. Untuk mengurangi ketidaknyamanan pasien maka diberikan tindakan manajemen nyeri berupa anestesi lokal dan pemberian analgesik. Penelitian ini bertujuan untuk menganalisis perbandingan efektivitas pemberian asam mefenamat dan natrium diklofenak sebelum pencabutan gigi terhadap durasi ambang nyeri setelah pencabutan gigi. Penelitian ini menggunakan desain penelitian klinis dengan rancangan case-control study. Pengambilan sampel menggunakan teknik purposive sampling berdasarkan kriteria inklusi dan ekslusi dengan total sampel 30 pasien: 10 pasien dalam kelompok kontrol tanpa perlakuan; 10 pasien dalam kelompok uji dengan asam mefenamat; dan 10 pasien dalam kelompok uji dengan natrium diklofenak. Penelitian dilaksanakan pada bulan Juli-Agustus 2016 di Rumah Sakit Gigi dan Mulut Unsrat. Hasil penelitian menunjukkan dari 30 sampel, 10 sampel yang tidak mengonsumsi analgesik apapun sebelum pencabutan memiliki rata-rata durasi ambang nyeri lebih rendah dibandingkan dengan sampel-sampel lain yang mengonsumsi analgesik sebelum pencabutan dengan selisih 2 jam 42 menit. Pasien dengan rata-rata durasi ambang nyeri terbesar ialah yang diberikan asam mefenamat yaitu 4 jam 11 menit dan yang diberikan
\end{abstract}


natrium diklofenak memiliki rata-rata durasi ambang nyeri sebesar 3 jam 49 menit dengan selisih 22 menit. Simpulan: Pemberian asam mefenamat sebelum pencabutan gigi memiliki efektivitas dan rata-rata durasi ambang nyeri yang lebih tinggi dibandingkan pemberian natrium diklofenak dengan selisih durasi ambang nyeri 2 jam 42 menit jika dibandingkan dengan kelompok tanpa pemberian analgesik.

Kata kunci: pencabutan gigi, asam mefenamat, natrium diklofenak, durasi ambang nyeri

Kesehatan gigi dan mulut hingga saat ini masih menjadi masalah bagi masyarakat di Indonesia, khususnya di provinsi Sulawesi Utara. Menurut data Riset Kesehatan Dasar (Riskesdas) Nasional tahun 2013, Sulawesi Utara merupakan satu dari beberapa provinsi di Indonesia dengan prevalensi tertinggi untuk masyarakat yang bermasalah gigi-mulut yaitu sebesar 31,6 $\%$. Jumlah ini meningkat jika dibandingkan dengan hasil Riskesdas pada tahun 2007 yaitu hanya sebesar $29,8 \%{ }^{1}$

Masalah gigi dan mulut umumnya merupakan masalah gigi berlubang yang seringkali membutuhkan tindakan perawatan yang lebih lanjut. Suatu tindakan pencabutan gigi dilakukan dengan berbagai indikasi, misalnya gigi dengan karies yang terlanjur meluas dan tidak dapat dirawat, fraktur mahkota atau sisa akar, atau pencabutan yang berhubungan dengan perawatan prostetik dan ortodontik. Pencabutan juga dapat diindikasikan apabila gigi tersebut dapat memicu timbulnya penyakit odontogenik lainnya seperti abses periodontal, kista, dan penyakit periapikal. ${ }^{2}$

Tindakan pencabutan dilakukan dengan teknik yang benar dan tidak menyebabkan rasa nyeri selama perawatan berlangsung merupakan suatu prosedur yang harus dilaksanakan sesuai dengan standar operasional prosedur (SOP). Adanya nyeri yang muncul saat perawatan tidak dapat dipungkiri meskipun telah dilakukan prosedur yang benar untuk mencegah keberadaan rasa nyeri. Di saat seperti ini, dokter gigi harus dapat melakukan diagnosis dan penanganan yang tepat untuk menentukan asal dari rasa nyeri tersebut dan bagaimana cara mengatasinya. $^{3}$

Untuk mengatasi nyeri pada pasien, dapat dilakukan bentuk manajemen nyeri berupa obat-obatan berupa analgesik yang diberikan untuk mengurangi rasa sakit sebelum atau sesudah pencabutan, dan anestesi lokal yang berguna untuk mengurangi rasa nyeri selama tindakan pencabutan berlangsung. Pemberian anestesi lokal dan tekniknya disesuaikan dengan kebutuhan dari masing-masing pasien. Analgesik sebagai salah satu manajemen nyeri terbagi menjadi dua kelompok besar, salah satunya ialah kelompok Non-steroidal anti inflammatory drugs (NSAID). Jenis NSAID yang paling sering digunakan dalam bidang kedokteran gigi untuk mengurangi nyeri pasca pencabutan atau tindakan bedah mulut ialah asam mefenamat, natrium diklofenak, ibuprofen, atau gabungan dari pemberian parasetamol dan jenis analgetik opioid. ${ }^{4-6 .}$

Asam mefenamat dan natrium diklofenak memiliki waktu awal kerja yang relatif hampir sama yaitu satu sampai satu setengah jam setelah pemberian oral dan memiliki durasi efek analgesik sekitar dua sampai empat jam. Asam mefenamat secara umum diresepkan untuk mengatasi nyeri akut yang dirasakan setelah efek anestesi mulai berkurang pada pasien pasca pencabutan, namun tidak memiliki efek signifikan dalam meredakan inflamasi yang terjadi di sekitar area soket gigi yang dicabut. Efek samping yang sering dilaporkan yaitu mual, muntah, atau gangguan ringan pada sistem pencernaan. Natrium diklofenak juga dapat diberikan untuk pasien pasca pencabutan gigi karena memiliki efek analgesik yang dapat meredakan rasa nyeri dan mengurangi inflamasi pada area soket gigi yang dicabut. Obat ini memiliki efek analgesik dengan durasi yang lebih panjang daripada asam mefenamat. Pada penggunaan natrium 
diklofenak sebaiknya diperhatikan kondisi kesehatan umum pasien karena memiliki efek samping yang lebih merugikan pada pasien dengan kelainan jantung atau gagal ginjal akut. Sejauh ini, pemberian natrium diklofenak memiliki efek samping saluran pencernaan yang lebih ringan daripada asam mefenamat. Perbandingan harga eceran tertinggi untuk kedua jenis obat menunjukkan perbedaan yang cukup besar, dimana asam mefenamat dijual dengan harga yang lebih terjangkau daripada harga natrium diklofenak. ${ }^{6,7}$

\section{BAHAN DAN METODE PENELITIAN}

Penelitian ini menggunakan desain penelitian klinis dengan rancangan casecontrol study. Pengambilan sampel menggunakan teknik purposive sampling berdasarkan kriteria inklusi dan eksklusi dengan total sampel 30 pasien: 10 pasien masuk dalam kelompok kontrol tanpa perlakuan; 10 pasien masuk dalam kelompok uji yang diberikan asam mefenamat; dan 10 pasien masuk dalam kelompok uji yang diberikan natrium diklofenak. Penelitian dilaksanakan pada bulan Juli-Agustus 2016 di Rumah Sakit Gigi dan Mulut Unsrat Manado. Pada pasien yang masuk dalam kelompok tanpa perlakuan, pengamatan dan pencatatan waktu dimulai ketika pasien menerima injeksi larutan anestesi hingga pasien merasa nyeri untuk pertama kali setelah tindakan pencabutan. Untuk kelompok uji yang diberikan analgesik berupa asam mefenamat maupun natrium diklofenak, pengamatan dan pencatatan waktu dilakukan mulai dari pasien meminum obat analgesik sebelum pencabutan, saat pasien menerima anestesi, hingga waktu dimana pasien merasa nyeri untuk pertama kali setelah tindakan pencabutan.

\section{HASIL PENELITIAN}

Pasien pencabutan gigi yang datang dan telah menandatangani lembar persetujuan menjadi sampel penelitian (informed consent) berjumlah 30 orang dan dibagi secara acak ke dalam tiga kelompok dengan jumlah masing-masing 10 orang.

Tabel 1. Karakteristik sampel berdasarkan jenis kelamin, kelompok umur, dan pemberian analgesik

\begin{tabular}{cccc}
\hline Karakteristik & & n & \% \\
\hline Jenis kelamin & Laki-laki & 8 & 26,4 \\
& Perempuan & 22 & 73,6 \\
& Total & 30 & 100 \\
\hline Kelompok & $17-25$ & 1 & 3 \\
Umur & $26-35$ & 6 & 20 \\
(tahun) & $36-45$ & 8 & 27 \\
& $46-55$ & 9 & 30 \\
& $56-65$ & 6 & 20 \\
& Total & 30 & 100 \\
\hline Pemberian & Kelompok tanpa perlakuan & 10 & 33,3 \\
Analgesik & Kelompok uji asam mefenamat & 10 & 33,3 \\
& Kelompok uji natrium diklofenak & 10 & 33,3 \\
& Total & 30 & 99,9 \\
\hline
\end{tabular}


Pangalila, Wowor, Hutagalung: Perbandingan efektivitas pemberian ...

Tabel 2 . Derajat nyeri pada sampel dalam kelompok uji dan kelompok kontrol berdasarkan Visual Analog Scale (VAS)

\begin{tabular}{ccccccc}
\hline \multirow{2}{*}{ Kategori } & \multicolumn{2}{c}{$\begin{array}{c}\text { Kelompok tanpa } \\
\text { perlakuan }\end{array}$} & \multicolumn{2}{c}{ Asam } & \multicolumn{2}{c}{ Natrium } \\
\cline { 2 - 7 } & $\mathrm{n}$ & $\%$ & $\mathrm{n}$ & $\%$ & $\mathrm{n}$ & $\%$ \\
\hline 0 & 0 & 0 & 0 & 0 & 0 & 0 \\
1 & 0 & 0 & 0 & 0 & 0 & 0 \\
2 & 0 & 0 & 3 & 30 & 2 & 20 \\
3 & 2 & 20 & 2 & 20 & 3 & 30 \\
4 & 3 & 30 & 2 & 20 & 4 & 40 \\
5 & 3 & 30 & 2 & 20 & 1 & 10 \\
6 & 2 & 20 & 1 & 10 & 0 & 0 \\
7 & 0 & 0 & 0 & 0 & 0 & 0 \\
8 & 0 & 0 & 0 & 0 & 0 & 0 \\
9 & 0 & 0 & 0 & 0 & 0 & 0 \\
10 & 0 & 0 & 0 & 0 & 0 & 0 \\
Total & 10 & 100 & 10 & 100 & 10 & 100 \\
\hline
\end{tabular}

Tabel 3. Durasi ambang nyeri berdasarkan waktu pemberian anestesi dan waktu munculnya rasa nyeri setelah pencabutan pada kelompok kontrol tanpa perlakuan

\begin{tabular}{cccc}
\hline Nomor & $\begin{array}{c}\text { Waktu Pemberian } \\
\text { Anestesi (WITA) }\end{array}$ & $\begin{array}{c}\text { Waktu munculnya } \\
\text { rasa nyeri (WITA) }\end{array}$ & $\begin{array}{c}\text { Durasi ambang nyeri } \\
\text { setelah pencabutan } \\
\text { (jam.menit) }\end{array}$ \\
\hline Regio Anterior & & \\
\hline 1 & 09.18 & 10.42 & 1.24 \\
2 & 09.41 & 11.35 & 1.54 \\
3 & 11.24 & 12.38 & 1.14 \\
4 & 11.37 & 12.30 & .53 \\
5 & 12.08 & 13.57 & 1.59 \\
\hline Rerata durasi ambang nyeri sampel regio anterior & 1.30 \\
\hline Regio Posterior & & 2.38 \\
\hline 6 & 10.47 & 13.25 & 2.25 \\
7 & 11.03 & 13.28 & 1.31 \\
8 & 11.22 & 12.53 & 2.52 \\
9 & 11.23 & 14.15 & 2.29 \\
10 & 12.04 & 14.33 & 2.23 \\
\hline Rerata durasi ambang nyeri sampel regio posterior & 1.56 \\
\hline Rerata durasi ambang nyeri kelompok kontrol \\
\hline
\end{tabular}


Tabel 4. Durasi ambang nyeri berdasarkan waktu pemberian analgesik, waktu pemberian anestesi dan waktu munculnya rasa nyeri setelah pencabutan pada kelompok uji asam mefenamat

\begin{tabular}{|c|c|c|c|c|c|}
\hline Nomor & $\begin{array}{c}\text { Waktu } \\
\text { pemberian } \\
\text { asam } \\
\text { mefenamat } \\
\text { (WITA) }\end{array}$ & $\begin{array}{c}\text { Waktu } \\
\text { pemberian } \\
\text { anestesi } \\
\text { (WITA) }\end{array}$ & $\begin{array}{c}\text { Waktu } \\
\text { munculnya } \\
\text { rasa nyeri } \\
\text { (WITA) }\end{array}$ & $\begin{array}{c}\text { Durasi } \\
\text { ambang } \\
\text { nyeri setelah } \\
\text { pencabutan } \\
\text { (jam.menit) }\end{array}$ & $\begin{array}{c}\text { Durasi } \\
\text { ambang } \\
\text { nyeri anestesi } \\
\text { (jam.menit) }\end{array}$ \\
\hline \multicolumn{6}{|c|}{ Regio anterior } \\
\hline 1 & 09.25 & 10.43 & 14.11 & 4.46 & 3.28 \\
\hline 2 & 09.34 & 11.08 & 14.26 & 4.52 & 3.18 \\
\hline 3 & 09.39 & 10.45 & 14.18 & 4.39 & 3.33 \\
\hline 4 & 09.48 & 10.57 & 13.44 & 3.56 & 2.47 \\
\hline 5 & 09.56 & 10.59 & 13.35 & 3.39 & 2.36 \\
\hline \multicolumn{4}{|c|}{ Rerata durasi ambang nyeri sampel regio anterior } & 4.22 & 3.08 \\
\hline \multicolumn{6}{|c|}{ Regio Posterior } \\
\hline 6 & 09.17 & 10.46 & 13.48 & 3.31 & 3.02 \\
\hline 7 & 09.19 & 10.24 & 13.37 & 4.18 & 3.13 \\
\hline 8 & 09.29 & 10.31 & 13.54 & 4.25 & 3.23 \\
\hline 9 & 10.08 & 11.27 & 14.59 & 3.51 & 3.32 \\
\hline 10 & 10.37 & 12.04 & 14.41 & 3.54 & 2.37 \\
\hline \multicolumn{4}{|c|}{ Rerata durasi ambang nyeri sampel regio posterior } & 4 & 3.09 \\
\hline \multicolumn{4}{|c|}{$\begin{array}{l}\text { Rerata durasi ambang nyeri kelompok uji asam } \\
\text { mefenamat }\end{array}$} & 4.11 & 3.08 \\
\hline
\end{tabular}

Tabel 5. Durasi ambang nyeri berdasarkan waktu pemberian analgesik, waktu pemberian anestesi dan waktu munculnya rasa nyeri setelah pencabutan pada kelompok uji natrium diklofenak

\begin{tabular}{|c|c|c|c|c|c|}
\hline Nomor & $\begin{array}{c}\text { Waktu } \\
\text { pemberian } \\
\text { natrium } \\
\text { diklofenak } \\
\text { (WITA) }\end{array}$ & $\begin{array}{c}\text { Waktu } \\
\text { pemberian } \\
\text { anestesi } \\
\text { (WITA) }\end{array}$ & $\begin{array}{c}\text { Waktu } \\
\text { munculnya } \\
\text { rasa nyeri } \\
\text { (WITA) }\end{array}$ & $\begin{array}{c}\text { Durasi ambang } \\
\text { nyeri setelah } \\
\text { pencabutan } \\
\text { (jam.menit) }\end{array}$ & $\begin{array}{c}\text { Durasi } \\
\text { ambang } \\
\text { nyeri anestesi } \\
\text { (jam. } \\
\text { menit) }\end{array}$ \\
\hline \multicolumn{6}{|c|}{ Regio Anterior } \\
\hline 1 & 09.07 & 10.21 & 13.32 & 4.25 & 3.11 \\
\hline 2 & 09.25 & 10.44 & 12.25 & 3 & 1.41 \\
\hline 3 & 09.36 & 10.40 & 13.03 & 3.27 & 2.23 \\
\hline 4 & 10.34 & 11.55 & 14.27 & 3.53 & 2.32 \\
\hline 5 & 10.51 & 11.43 & 14.12 & 3.21 & 2.29 \\
\hline \multicolumn{4}{|c|}{ Rerata durasi ambang nyeri sampel regio anterior } & 3.37 & 2.27 \\
\hline \multicolumn{6}{|c|}{ Regio Posterior } \\
\hline 6 & 09.13 & 10.30 & 13.22 & 4.09 & 2.52 \\
\hline 7 & 09.16 & 10.28 & 13.36 & 4.20 & 3.08 \\
\hline 8 & 09.29 & 10.42 & 13.18 & 3.49 & 2.36 \\
\hline 9 & 09.38 & 11.07 & 14.26 & 4.28 & 3.19 \\
\hline 10 & 10.25 & 11.44 & 13.52 & 3.27 & 2.08 \\
\hline \multicolumn{4}{|c|}{ Rerata durasi ambang nyeri sampel regio posterior } & 4.03 & 2.49 \\
\hline \multicolumn{4}{|c|}{ Rerata durasi ambang nyeri kelompok uji natrium diklofenak } & 3.49 & 2.38 \\
\hline
\end{tabular}


Pangalila, Wowor, Hutagalung: Perbandingan efektivitas pemberian ...

Tabel 6. Rerata durasi ambang nyeri berdasarkan jenis kelamin dan kelompok umur sampel penelitian

\begin{tabular}{cccc}
\hline Karakteristik & n & $\begin{array}{c}\text { Rerata durasi } \\
\text { ambang nyeri } \\
\text { (jam.menit) }\end{array}$ \\
\hline Jenis Kelamin & Laki-laki & 8 & 2.46 \\
& Perempuan & 22 & 1.55 \\
\hline Kelompok & $17-25$ & 1 & 4.25 \\
usia & $26-35$ & 6 & 2.36 \\
(tahun) & $36-45$ & 8 & 3.02 \\
& $46-55$ & 9 & 3.58 \\
& $56-65$ & 6 & 3.13 \\
\hline
\end{tabular}

Tabel 7. Selisih durasi ambang nyeri kelompok uji analgesik asam mefenamat dan natrium diklofenak berdasarkan rerata durasi ambang nyeri

\begin{tabular}{cc}
\hline Pemberian analgesik & Rerata (jam.menit) \\
\hline Kelompok uji asam mefenamat & 4.11 \\
Kelompok uji natrium diklofenak & 3.49 \\
Selisih & .22 \\
\hline
\end{tabular}

\section{BAHASAN}

Pada penelitian ini didapatkan keseluruhan sampel sebanyak 30 orang yang terdiri dari 8 orang laki-laki $(26,4 \%)$ dan 22 orang perempuan $(73,6 \%)$. Berdasarkan jenis kelamin didapatkan bahwa rerata durasi ambang nyeri pada pasien berjenis kelamin laki-laki 2 jam 46 menit dan pasien perempuan 1 jam 55 menit, yang menunjukkan bahwa laki-laki memiliki tingkat sensitivitas yang lebih rendah daripada wanita, sehingga laki-laki tidak merasakan nyeri lebih cepat dari pada perempuan. Hal ini sesuai dengan penelitian yang dilakukan oleh Rokyta dan Yamamotova $^{8}$ yang menyimpulkan bahwa perbedaan sensitivitas rasa nyeri antara laki-laki dan perempuan cukup terlihat dengan pengukuran durasi ambang nyeri (threshold) yang menunjukkan bahwa perempuan memiliki durasi ambang nyeri yang lebih rendah daripada laki-laki, memiliki sensitivitas yang lebih tinggi daripada laki-laki, dan toleransi rasa nyeri yang lebih rendah daripada laki-laki.

Berdasarkan kelompok usia, terdiri dari rentang usia 17-25 tahun sebanyak 1 orang (3\%), 26-35 tahun sebanyak 6 orang (20\%), 36-45 tahun sebanyak 8 orang (27\%), 46-55 tahun sebanyak 9 orang (30 $\%)$ dan 56-65 tahun sebanyak 6 orang (20\%). Pemberian analgesik terdiri dari tiga kelompok, kelompok tanpa perlakuan sebanyak 10 orang $(33,3 \%)$, kelompok uji asam mefenamat sebanyak 10 orang $(33,3 \%)$ dan kelompok uji natrium diklofenak sebanyak 10 orang $(33,3 \%)$. Hasil penelitian menunjukkan bahwa kelompok usia dewasa muda dari umur 1725 tahun memiliki durasi ambang nyeri yang paling tinggi yaitu 4 jam 25 menit dan durasi ambang nyeri yang paling rendah dialami oleh kelompok usia 26-35 tahun. Kelompok usia yang juga memiliki ratarata durasi ambang nyeri tinggi ialah kelompok usia 46-55 tahun yaitu sebesar 3 jam 58 menit. Penelitian yang dilakukan Wandner et al. ${ }^{9}$ juga turut membandingkan beberapa kelompok usia dalam menanggapi stimulus nyeri, dengan simpulan bahwa kelompok usia yang lebih tua memiliki sensitivitas yang lebih tinggi jika dibandingkan dengan kelompok usia dewasa muda. Selain itu juga dinyatakan 
bahwa ada beberapa faktor dan sudut pandang yang turut memengaruhi persepsi nyeri masing-masing individu sehingga hasil penelitian tersebut bukan merupakan suatu patokan.

Dari data pada Tabel 2, nyeri yang dirasakan oleh sampel setelah tindakan pencabutan gigi yang masuk dalam kelompok tanpa perlakuan dengan kategori nyeri 3 sebanyak 2 orang (20\%), kategori nyeri 4 sebanyak 3 orang $(30 \%)$, kategori nyeri 5 sebanyak 3 orang $(30 \%)$ dan kategori nyeri 6 sebanyak 2 orang (20\%). Nyeri pada sampel yang termasuk dalam kelompok uji asam mefenamat dengan kategori nyeri 2 sebanyak 3 orang (30\%), kategori nyeri 3 sebanyak 2 orang (20\%), kategori nyeri 4 sebanyak 2 orang (20\%), kategori nyeri 5 sebanyak 2 orang (20\%) dan kategori nyeri 6 sebanyak 1 orang $(10 \%)$. Nyeri pada sampel yang termasuk dalam kategori kelompok uji natrium diklofenak dengan kategori 2 sebanyak 2 orang (20\%), kategori 3 sebanyak 3 orang (30\%), kategori 4 sebanyak 4 orang $(40 \%)$ dan kategori 5 sebanyak 1 orang (10\%). Berdasarkan penilaian skala analog visual (VAS) terlihat bahwa pasien pada kelompok kontrol tanpa perlakuan memiliki persepsi nyeri dalam skala 3 sampai skala 6 dan masuk pada kategori nyeri sedang; kelompok uji natrium diklofenak memiliki persepsi nyeri dalam skala 2 sampai skala 5 dan masuk pada kategori nyeri ringan. Adanya penurunan dalam pengukuran skala analog visual dalam persepsi nyeri disebabkan karena adanya pemberian analgesik berupa natrium diklofenak yang selain membantu meningkatkan durasi ambang namun juga turut memperkecil sensitivitas nyeri tersebut. ${ }^{10}$ Pasien pada kelompok uji asam mefenamat memiliki skala persepsi nyeri yang lebih bervariasi mulai dari skala 2 hingga skala 6 dan masuk dalam kategori nyeri ringan dan nyeri sedang. Satu responden yang masuk dalam kategori nyeri sedang dengan skala analog visual 6 berusia 60 tahun dan memiliki sensitivitas yang berlebihan terhadap prosedur pencabutan gigi, sehingga meskipun pemberian analgesik berupa asam mefenamat telah diberikan pasien masih merasakan rasa nyeri yang didefinisikan ke dalam kategori nyeri sedang. Hasil penelitian yang dilakukan Greenspan et al. ${ }^{11}$ pada responden di Kanada dan penelitian oleh Wandner et al. ${ }^{9}$ di Amerika menunjukkan bahwa sensitivitas nyeri yang ditunjukkan memang berbeda secara spesifik bagi setiap orang namun dalam keseluruhannya semakin bertambahnya usia seseorang maka sensitivitas rasa nyeri akan lebih bertambah.

Berdasarkan pemberian analgesik sebelum pencabutan gigi didapat hasil bahwa pasien yang diberikan analgesik memiliki durasi ambang nyeri yang lebih tinggi dibandingkan yang tidak diberikan analgesik sebelum tindakan pencabutan gigi. Kelompok uji analgesik asam mefenamat memiliki durasi ambang nyeri yang paling tinggi yaitu sebesar 4 jam 11 menit dan kelompok uji analgesik natrium diklofenak memiliki durasi ambang nyeri sebesar 3 jam 49 menit. Durasi ambang nyeri dari kelompok kontrol tanpa perlakuan hanya sebesar 1 jam 29 menit. Hal ini membuktikan bahwa pemberian analgesik sebelum tindakan pencabutan gigi memiliki pengaruh yang cukup besar dalam manajemen nyeri saat tindakan pencabutan gigi, terlebih khusus pada pasien dengan pemberian obat asam mefenamat. Hasil serupa juga ditunjukkan oleh penelitian yang dilakukan oleh Febriana $^{12}$ yaitu adanya selisih durasi ambang nyeri 1 jam 17 menit lebih lama pada pasien yang mengonsumsi asam mefenamat sebelum tindakan pencabutan dengan yang tidak mengonsumsi analgesik apapun. Penelitian yang dilakukan oleh Kudaravalli dan Deshpande ${ }^{6}$ di India tentang perbandingan natrium diklofenak dan aseklofenak dalam manajemen nyeri pasca pencabutan menyatakan bahwa pasien dengan pemberian natrium diklofenak memiliki intensitas nyeri yang berkurang $27 \%$ sedangkan pasien yang diberikan aseklofenak memiliki intensitas nyeri yang berkurang sekitar $40 \%$ dalam jangka waktu 8 jam setelah pemberian 
analgesik. Adanya variasi hasil penelitian juga melibatkan keterampilan operator dalam menjalankan prosedur pencabutan gigi, termasuk dengan teknik anestesi yang dilakukan pada pasien.

Pemberian analgesik, terlebih khusus NSAID memiliki beberapa golongan yang bekerja sesuai dengan penghambatan enzim siklooksigenase (COX) untuk menghantarkan dan meneruskan stimulus nyeri. NSAIDs digolongkan ke dalam tiga golongan yaitu penghambat COX nonselektif yang dapat menghambat enzim COX isoform 1 dan COX isoform 2, COX2 preferential yaitu penghambat yang lebih cenderung efektif bekerja pada COX-2 namun masih memiliki efek hambat pada COX-1, dan COX-2 selektif yaitu penghambat yang sepenuhnya bekerja pada penghambatan enzim COX isoform 2 . Asam mefenamat masuk dalam NSAIDs COX non-selektif yang menghambat stimulus nyeri pada sebagian besar organ yang melakukan sekresi enzim siklooksigenase 1, yang artinya stimulus nyeri dapat langsung dihambat sepenuhnya oleh asam mefenamat ketika rangsangan pertama kali diberikan. Natrium diklofenak termasuk jenis analgesik COX-2 preferential yakni penghambat enzim COX-2 yang bekerja pada jaringan yang mengalami trauma namun molekul obatnya belum sepenuhnya menghambat stimulus nyeri ketika rangsangan muncul. ${ }^{13-19}$ Oleh karena itu, hal mengenai perbedaan cara kerja asam mefenamat dan natrium diklofenak dalam penghambatan stimulus nyeri menyebabkan terdapat selisih 22 menit lebih lama pada pasien dengan pemberian analgesik asam mefenamat sebelum pencabutan dibandingkan pasien dengan pemberian analgesik natrium diklofenak.

\section{SIMPULAN}

Dari hasil penelitian ini dapat disimpulkan bahwa:

1. Pasien yang diberikan analgesik berupa asam mefenamat memiliki durasi ambang nyeri terbesar yaitu 4 jam 11 menit dengan selisih 22 menit dari pasien yang diberikan analgesik natrium diklofenak yang memiliki durasi ambang nyeri sebesar 3 jam 49 menit.

2. Pada pasien yang diberikan analgesik sebelum tindakan pencabutan gigi, terdapat selisih durasi ambang nyeri sebesar 2 jam 42 menit jika dibandingkan dengan pasien yang tidak diberikan analgesik apapun sebelum tindakan pencabutan gigi

\section{SARAN}

Bagi mahasiswa profesi agar lebih memperhatikan manajemen nyeri pada pasien termasuk pemberian analgesik yang sesuai bagi kondisi kesehatan pasien dan pemberian anestesi lokal yang tepat sasaran. Efektivitas waktu dalam menangani pasien per operator juga harus diperhitungkan dengan baik karena memengaruhi lama tidaknya durasi ambang nyeri yang akan muncul setelah pasien diberikan analgesik.

\section{DAFTAR PUSTAKA}

1. Badan Penelitian dan Pengembangan Kesehatan, Kementerian Kesehatan Republik Indonesia. Riset Kesehatan Dasar. 2013; p. 110-11.

2. Datarkar AN. Exodontia Practice. New Delhi: Jaypee Brother Medical Publisher, 2007; p. 31-44.

3. Pedlar J, Frame JW. Oral and Maxillofacial Surgery: An Objectivebased Textbook $\left(2^{\text {nd }}\right.$ ed). Churchill Livingstone: Elsevier, 2007; p. 12-4.

4. Hargreaves K, Abbott PV. Drugs for pain management in dentistry. Aus Dent J. 2005;50(4 Suppl 2):S14-22.

5. Malamed SF. Handbook of Local Anesthesia (6th ed). Missouri: Elsevier, 2013; p. 1-23.

6. Kudaravalli J, Narayan D, Vijayalakhsmi G. Efficacy and Safety of Diclofenac Sodium and Aceclofenac in Controlling Post Extraction Dental Pain: A Randomized Open Label Comparative Study. J Pharmacol Toxicol; 2011;6(5):541-47.

7. Departemen Farmakologi dan Terapeutik Universitas Indonesia. Farmakologi dan Terapi (5th ed). Jakarta: Universitas Indonesia, 2007; p. 21019, 230-40. 
8. Rokyta R, Yamamotova A. Sex differences in pain perception and interpretation. Act Nerv Super Rediviva. 2013;55(3):125-8.

9. Wandner LD, Scipio CD, Hirsh AT, Torres CA, Robinson ME. The perception of pain in others: How gender, race, and age influence pain expectations. Pain. 2012;13(3):220-7.

10.Todd P, Sorkin E. Diclofenac Sodium: Drug Evaluation. Springer Link November 2012;35(3):244-85.

11.Greenspan J, Craft RM, LeResche L, Arendt-Nielsen L, Berkley $\mathbf{K J}$, Fillingim RB, et al. Studying sex and gender differences in pain and analgesia: A consensus report. Pain. 2007:132(Suppl 1):S26-45.

12.Febriana, Posangi J, Hutagalung B. Uji efek pemberian asam mefenamat sebelum pencabutan gigi terhadap durasi ambang nyeri setelah pencabutan gigi. eG. 2015;3(2):5616.

13.Raj JD, Ramesh S. Evaluation of the anesthetic efficacy of inferior alveolar nerve blocks in dental patients - A systematic review. J Dent Med Sci. 2013;8(6): 10-7.

14. Grosser T, Smyth E, FitzGerald GA. Anti-inflammatory, antipyretic, and analgesics agents; Pharmacotherapy of gout. In: Brunton LL, editor. Goodman and Gillman's The Pharmacological Basis of
Therapeutics (12th ed). California: McGraw Hill, 2011; p. 959-89.

15.Ngeow WC, Ong ST. Are COX-2 inhibitors a solution to problems associated with current oral analgesics? A revisit with a perspective of local need. Malays Dent J. 2008;29(2):84.

16.Kresnadi D, Mulyo K. Perbandingan pengaruh pemberian analgetik $\mathrm{COX}-2$ dengan asam mefenamat terhadap rasa nyeri pasca odontektomi (Impaksi Kelas 1, molar 3 rahang bawah). Jurnal Media Medika Muda. 2016;5(1):59-65.

17.Chang DJ, Desjardins P, Chen E, Polis AB, McAvoy M, Mockoviak SH, et al. Comparison of the analgesic efficacy of rofecoxib and entericcoated diclofenac sodium in the treatment of postoperative dental pain: A randomized, placebo controlled clinical trial. Clin Ther J. 2007;24(4):490-503.

18.Hersh EV, Desjardins PJ, Trummel CL, Cooper SA. Nonopioid analgesics, nonsteroidal anti-inflammatory drugs, and antirheumatic and antigout drugs. In: Yagiela AJ, Dowd FJ, editors. Pharmacology and Therapeutics for Dentistry. Missouri: Mosby Elsevier, 2011; p. 324-48.

19.Darnis D, Veyrac G,Jolliet P. The special case of diclofenac. Enliven Arch. 2014;1(1):1-3. 